\title{
KARAKTERISTIK DIAMETER AEROSOL LURUHAN THORON DENGAN IMPAKTOR BERTINGKAT
}

\author{
Eko Mulyadi \\ STMIK EL RAHMA Jl. Sisingamangaraja 76 Yogyakarta
}

\begin{abstract}
ABSTRAK
KARAKTERISTIK DLAMETER AEROSOL LURUHAN THORON DENGAN IMPAKTOR BERTINGKAT. Telah dikembangkan penelitian tentang Thoron dan luruhannya. Pada penelitian ini telah dilakukan pengukuran diameter aerosol luruhan Thoron dalam ruang tertutup dengan perlakuan chamber tertutup dan terbuka. Pengukuran diameter aerosol luruhan Thoron dilakukan menggunakan impaktor Andersen 13 tingkat dengan laju alir 3 liter permenit. Setiap tingkat impaktor dicacah dengan spektrometri gamma HP-Ge pada energi $238,6 \mathrm{keV}$ (isotop Pb-212). Hasil studi menunjukkan bahwa ikatan aerosol luruhan Thoron terdistribusi bimodal dengan Activity Median Aerodynamic Diameter (AMAD) adalah $(0,1 \pm 0,004) \mu \mathrm{m}$ fraksi $36 \%$ dan $(7,0 \pm 5,6) \mu m$ fraksi $6 \%$ dengan perlakuan chamber tertutup dan $A M A D(0,1 \pm 0,006) \mu$ m fraksi $39 \%$ dan $(4,0 \pm$ 3,0) $\mu \mathrm{m}$ fraksi $8 \%$ dengan perlakuan chamber terbuka.
\end{abstract}

\section{ABSTRACT}

CHARACTERISTIC OF AEROSOL DLAMETER OF ATTACHED THORON DECAY WITH CASCADE IMPACTOR. The attention was shifted to Thoron and it's decay products. In this work the measurement of their attachment diameter in trapped air and ventilated air has been performed. Andersen's 13 stage cascade impactor was used at 3 liter perminute flow rate. Each stage of the impactor was counted using HP-Ge detector gamma spectroscopy at $238.6 \mathrm{keV}$, being the most dominant gamma production with sufficiently long live. The results show that the diameter distribution is slightly bimodal having Activity Median Aerodynamic Diameter (AMAD) of $(0.1 \pm$ $0.004) \mu \mathrm{m}$ at $36 \%$ fraction and $(7.0 \pm 5.6) \mu \mathrm{m}$ at $6 \%$ fraction for trapped air and AMAD $(0.1 \pm$ $0.006) \mu m$ at $39 \%$ fraction and (4.0 \pm 3.0$) \mu m$ at $8 \%$ fraction for ventilated air.

\section{PENDAHULUAN}

$\mathrm{T}$ horon (Radon 220) berupa gas sehingga dengan mudah akan lepas bebas di udara. Umur paro gas Thoron 55,6 detik, maka sewaktu di udara akan meluruh menghasilkan Po-216 (ThA), Pb-212 (ThB), Bi-212 (ThC) dan Po-212 (ThC') yang berupa partikel aerosoi yang akan terhisap oleh saluran pernafasan yang bergantung dari ukuran aerodinamis partikel $^{[1]}$, gas Thoron berasal dari luruhan induk Th-232 (Gambar 1).

Tujuan penelitian ini untuk mengetahui karakteristik diameter aerosol luruhan Thoron (Rn-220), dalam pengukuran diameter luruhan Thoron yang diukur adalah $\mathrm{Pb}-212$ ( ThB) yang terikat dengan udara (attachment), karena $\mathrm{Pb}-212$ memiliki waktu paro 10,6 jam terbesar diantara luruhan Thoron dan memiliki energi gamma 238,6 keV. Pengukuran dilakukan dalam ruang tertutup dengan perlakuan sumber Thoron chamber tertutup dan chamber terbuka, diasumsikan kelakuan luruhan Thoron tersebar merata di dalam chamber. Data yang diperoleh untuk memantau aerosol radioaktif alam atau buatan.

Dalam penelitian digunakan metode eksperimen untuk sampling data dengan impaktor Andersen 13 tingkat yang memiliki ketelitian mengukur diameter partikel rentang 0,08-35 $\mu \mathrm{m}$ dengan mekanisme impaksi. Pelat impaksi setiap tingkat menggunakan plastik mylar merk yashica $( \pm 81 \mathrm{~mm})$ dan tingkat terakhir menggunakan filter HEPA (High Efficiency Particulate Air), kemudian data diolah untuk mengetahui aktivitas median diameter (AMAD) dan distribusi frekuensi. 


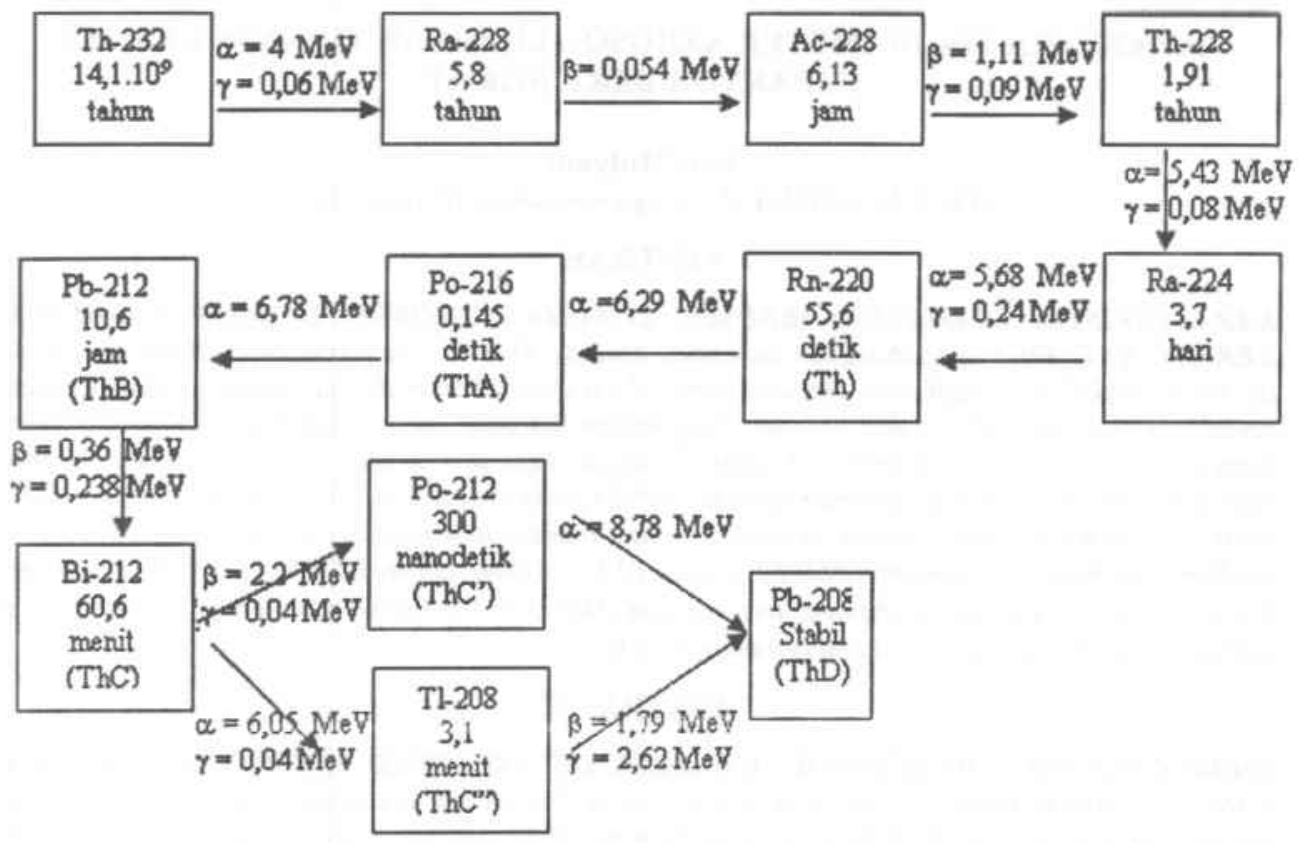

Gambar 1. Skema peluruhan radioaktif alami Th-232

\section{PENGUKURAN DIAMETER AEROSOL DENGAN IMPAKTOR BERTINGKAT}

Impaktor adalah sebuah nosel atau jet yang diarahkan ke pelat impaksi. Aliran yang memasuki nosel dipercepat dan kemudian oleh pelat impaksi aliran dibelokkan $90^{\circ}$, sehingga partikel dengan ukuran lebih besar dari harga diameter pangkas (cut-size) karena kelembamannya tidak dapat mengikuti garis alir sehingga menumbuk dan mengendap pada pelat impaksi (Gambar 2).

Namun keadaan di atas tidak pasti karena ada kebolehjadian partikel dengan ukuran di atas diameter pangkas yang masih dapat lolos daerah arsiran bagian atas dan partikel dengan ukuran kurang dari diameter pangkas yang menumbuk dan terendapkan pada daerah arsiran bagian bawah (Gambar 3). Pada impaktor bertingkat partikel yang lolos dari satu tingkat dilewatkan pada tingkat berikutnya. Tingkat ini mempunyai ukuran karakteristik yang berbeda dari tingkat sebelumnya, sedemikian sehingga diameter pangkas pada tingkat tersebut kurang dari diameter sebelumnya. Pada tingkat akhir pelat impaksi digantikan dengan filter HEPA (Gambar 4).

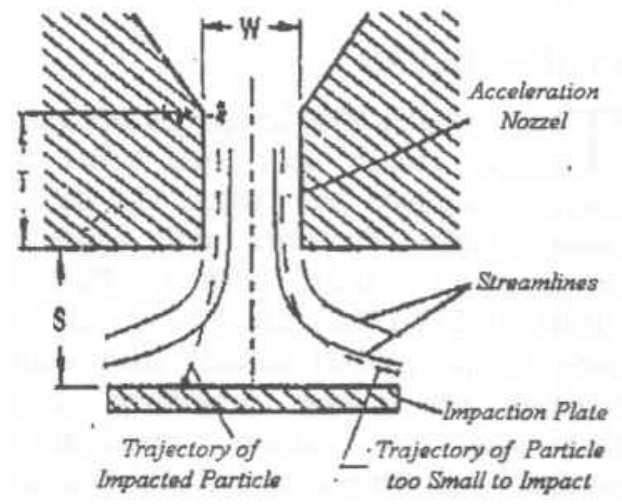

Gambar 2. Impaktor konvensional 


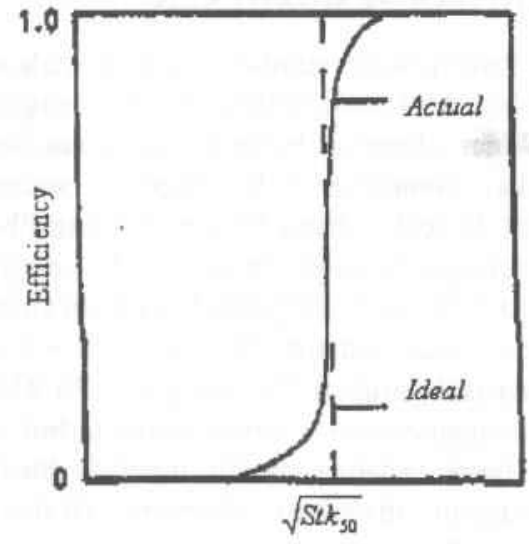

Gambar 3. Kurva efisiensi koleksi

Dengan cara demikian partikel yang masuk impaktor bertingkat dapat diklasifikasikan banyaknya partikel yang mengendap pada setiap tingkat dapat ditentukan dengan melakukan pencacahan pelat impaksi dengan spektrometri gamma atau alfa untuk radioaktif dan penimbangan pelat impaksi untuk non radioaktif. Efisiensi pengendapan partikel menumbuk pelat impaksi merupakan fungsi dari bilangan Stokes (Stk) yang didefinisikan sebagai nisbah jarak henti partikel dan diameter nosel yang dinyatakan dengan persamaan (1), fungsi Stokes :

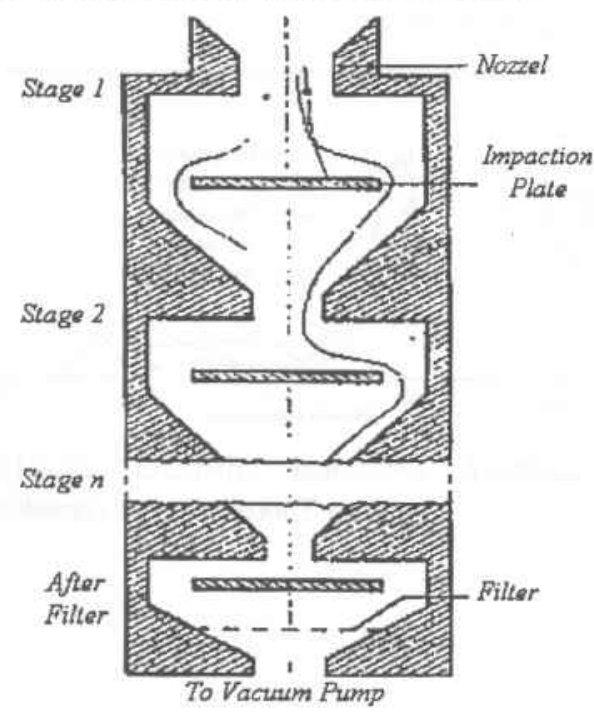

Gambar 4. Impaktor bertingkat
$\mathrm{Stk}=\frac{\rho \mathrm{P} \cdot \mathrm{DP} \mathrm{p}^{2} \cdot \mathrm{V} \cdot \mathrm{C}}{9 \cdot \mathrm{\eta} \cdot \mathrm{W}}$

dengan $\rho_{p}=$ kerapatan partikel $\left(\mathrm{Kg} \cdot \mathrm{m}^{-3}\right)$, $\mathrm{D}_{\mathrm{p}}=$ diameter pangkas (m), $\eta=$ viskositas $\left(\mathrm{Kg} \cdot \mathrm{m}^{-1} \cdot \mathrm{s}^{-1}\right), \mathrm{W}=$ diameter nosel $(\mathrm{m})$, $\mathrm{V}=$ kecepatan udara $=\frac{\mathrm{q}}{\pi \cdot\left(\frac{\mathrm{W}}{2}\right)^{2}}$,

$\mathrm{C}=$ faktor koreksi gelincir $=$ $1+2,492\left(\frac{\lambda}{D P}\right)+0,84 \cdot\left(\frac{\lambda}{D_{P}}\right) e^{-0,435 \cdot \frac{D_{P}}{\lambda}}$, $\lambda=$ lintasan bebas rerata dari gas, $\mathrm{q}=$ laju alir udara $\left(\mathrm{m}^{3} / \mathrm{s}\right)$.

Koleksi karakteristik dari tingkat impaktor tertentu adalah dengan efisiensi $50 \%$ artinya $50 \%$ partikel dengan diameter tertentu mengendap pada pelat impaksi dan selebihnya lolos. Diameter partikel pada keadaan tersebut dikenal dengan diameter pangkas pada efisiensi $50 \%\left(\mathrm{D}_{\mathrm{p} 50}\right)$ dan bilangan Stk $_{50}$ sesuai dengan persamaan (2), $\mathrm{D}_{\mathrm{p} 50}$ dapat dijabarkan sebagai berikut : DP50 $=\sqrt{\frac{9 . \eta \cdot W}{\rho P . V . C} \sqrt{\text { Stk50 }}}$

Jika harga $\sqrt{\text { Stk50 }}$ diketahui, maka diameter pangkas $\mathrm{D}_{\mathrm{p} 50}$ dapat dihitung untuk impaktor bertekanan rendah harga $\sqrt{\text { Stk50 }}$ berkisar 0,497-0,545. Karakteristik impaktor bertekanan rendah Andersen 13 tingkat mampu mengukur diameter partikel aerosol 0,08-35 $\mu \mathrm{m}$, impaktor dioperasikan pada beda tekanan $114 \mathrm{mmHg}(0,15 \mathrm{~atm})$, laju hisap 3 liter per menit.

\section{TATA KERJA}

Sebelum dilakukan penelitian ruangan/ chamber dibersihkan dahulu dengan vacuum cleaner, kemudian sumber Thoron disimpan dalam chamber selama \pm 4 minggu untuk mencapai keseimbangan Radium dan anak luruhnya ${ }^{[3]}$.

Urutan kerja dalam penelitian :

1. Menyiapkan pelat impaksi

Eko Mulyadi, dkk

\section{PERPUSTAKAAN}


2. Plastik mylar yashica (Fuji-Japan) diameter $\pm 81 \mathrm{~mm}$ digosok dengan alkohol teknis.

3. Pelat impaksi/plastik mylar dan filter dipasang pada impaktor bertekanan rendah model 3551 (Andersen, Inc. USA) mulai dari tingkat LF,L5,L4, L3,L2,L1 kemudian 7,6,5,4,3,2,1,0 dan alat dirangkai (Gambar 5)

4. Mengambil cuplikan radioaktif dari kotak sumber Thoron, sumber Thoron digunakan kaos lampu petromak.

5. Cuplikan dialirkan ke impaktor bertingkat yang telah dihubungkan dengan pompa hisap General Electric 230 Volt selama 60 menit dengan laju alir $3 \mathrm{lpm}$ dan beda tekanan $114 \mathrm{mmHg}$.

6. Setelah pencuplikan berakhir plastik mylar dan filter HEPA dimasukkan ke dalam plastik seal.

7. Kemudian dilakukan pencacahan plastik mylar dan filter HEPA menggunakan spektrometri gamma HP-Ge (Ortec, USA) setiap tingkat selama 10 menit.

8. Data hasil cacahan diolah menjadi data distribusi diameter (fraksi) terhadap diameter.

9. Mengulangi langkah 1 sampai dengan 7 sebanyak 5 kali percobaan untuk chamber tertutup dan sebanyak 5 kali percobaan untuk chamber terbuka.

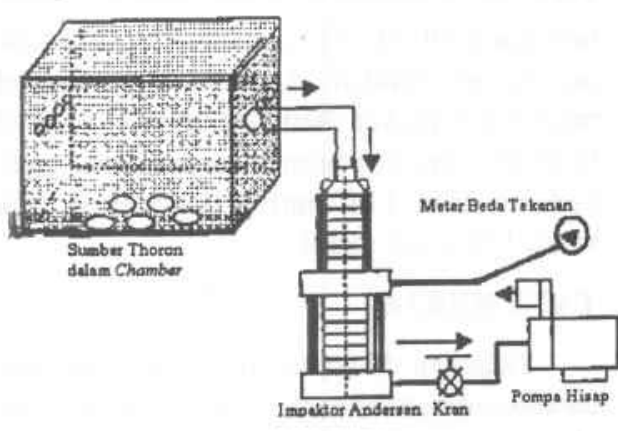

Gambar 5. Rangkaian alat-alat penelitian

\section{HASIL DAN PEMBAHASAN}

Pencuplikan sumber Thoron dalam chamber dilakukan selama 1 jam dengan perlakuan chamber tertutup dan chamber terbuka, kemudian pelat impaksi setiap tingkat dicacah selama 10 menit isotop Pb212 sebagai luruhan Thoron pada energi gamma $238,6 \mathrm{keV}$. Diperoleh data cacahan terbesar pada rentang diameter $0,08-0,1$ $\mu \mathrm{m}$ aerosol luruhan Thoron yaitu $\mathrm{Pb}-212$ baik dengan chamber tertutup atau terbuka. Data hasil cacahan diolah menjadi hasil perhitungan distribusi diameter (fraksi) terhadap diameter.

Dari Gambar 6 diperoleh percobaan 1 sampai dengan percobaan 5 adalah karakteristik distribusi bimodal (dua puncak dominan) dengan diameter AMADl adalah $0,09-0,10 \mu \mathrm{m}$ dengan fraksi $24-48 \%$, diameter AMAD2 adalah $2-16 \mu \mathrm{m}$ dengan fraksi $3-9 \%$ untuk perlakuan sumber Thoron chamber tertutup. Dari Gambar 7 juga diperoleh dari percobaan 1 sampai dengan percobaan 5 adalah karakteristik distribusi bimodal dengan diameter AMAD1 rentang $0,08-0,10 \mu \mathrm{m}$ dengan fraksi 35 $45 \%$, diameter AMAD2 rentang $2-10 \mu \mathrm{m}$ dengan fraksi $4-16 \%$ untuk perlakuan chamber terbuka.

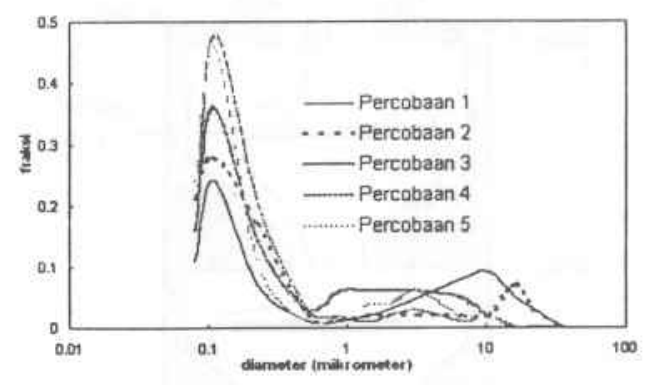

Gambar 6. Distribusi diameter $\mathrm{Pb}-212$ luruhan Thoron dengan chamber tertutup 


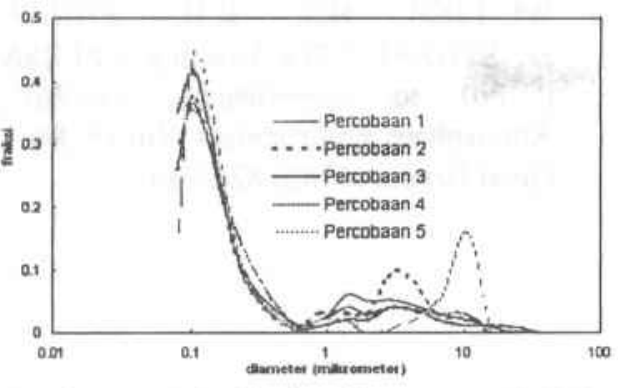

Gambar 7. Distribusi diameter $\mathrm{Pb}-212$ luruhan Thoron dengan chamber terbuka

Perbandingan hasil diameter rata-rata luruhan Thoron $(\mathrm{Pb}-212)$ dengan chamber tertutup adalah $(0,1 \pm 0,004) \mu \mathrm{m}$ fraksi $36 \%$ dan $(7,0 \pm 5,6) \mu \mathrm{m}$ fraksi $6 \%$, dan diamater rata-rata chamber terbuka adalah $(0,1 \pm 0,006) \mu \mathrm{m}$ fraksi $39 \%$ dan $(4,0 \pm$ $3,0) \mu \mathrm{m}$ fraksi $8 \%$ (Gambar 8). Karakteristik distribusi diameter $\mathrm{Pb}-212$ sebagai luruhan Thoron di dalam chamber dengan perlakuan terbuka dan tertutup diperoleh distribusi bimodal. Hasil ratarata distribusi diameter AMAD1 dengan fraksi terbesar pada diameter rata-rata $(0,1$ $\pm 0,004) \mu \mathrm{m}$ dan $(0,1 \pm 0,006) \mu \mathrm{m}$, untuk rata-rata diameter AMAD2 perlakuan tertutup lebih besar dari perlakuan terbuka hal ini disebabkan karena keadaan chamber tertutup sehingga cluster tidak dipengaruhi oleh tekanan udara dari luar, saat terbuka keadaan cluster dipengaruhi oleh tekanan udara dari luar sehingga diameternya semakin mengecil. Hasil penelitian distribusi diameter dibandingkan hasil penelitian sebelumnya (Tabel 1).

Tabel 1. Perbandingan hasil penelitian diameter aerosol luruhan thoron dalam chamber

\begin{tabular}{|l|c|c|}
\hline \multicolumn{1}{|c|}{ Referensi } & $\begin{array}{c}\text { Diameter } \\
(\mu \mathrm{m})\end{array}$ & $\begin{array}{c}\text { Metode } \\
\text { Pengukuran }\end{array}$ \\
\hline Lassen and Rau (1960) & $0,04-0,6$ & Diffusi battery \\
\hline $\begin{array}{l}\text { Lassen and Weicksel } \\
(1961)\end{array}$ & $0,7-5$ & Eletrostatics \\
\hline Mohnen (1967) & $0,06-0,1$ & Mobility analyzer \\
\hline Porstendorfer(1968) & $0,1-2$ & Tabung diffusi \\
\hline Porstendorfer et al (1979) & $0,009-4,5$ & Diffusi battery \\
\hline
\end{tabular}

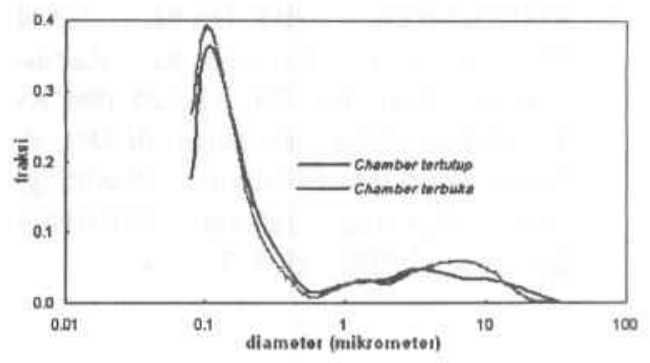

Gambar 8. Distribusi diameter rata-rata chamber tertutup dan terbuka

\section{KESIMPULAN}

1. Karakteristik distribusi diameter aerosol $\mathrm{Pb}-212$ sebagai luruhan Thoron dalam chamber terdistribusi paling sedikit bimodal.

2. Diameter rata-rata hasil penelitian dengan perlakuan chamber tertutup $(0,1$ $\pm 0,004) \mu \mathrm{m}$ fraksi $36 \%$ dan $(7,0 \pm 5,6)$ $\mu \mathrm{m}$ fraksi $6 \%$ dan chamber terbuka $(0,1$ $\pm 0,006) \mu \mathrm{m}$ fraksi $39 \%$ dan $(4,0 \pm 3,0)$ $\mu \mathrm{m}$ fraksi $8 \%$.

3. Hasil penelitian distribusi diameter luruhan Thoron mendekati hasil penelitian yang telah dilakukan sebelumnya.

\section{UCAPAN TERIMA KASIH}

Setelah berakhirnya penelitian ini diucapkan terima kasih kepada Kepala dan para staf Puslitbang Keselamatan Radiasi dan Biomedika Nuklir BATAN Aplikasi Isotop Pasar Jumat Jakarta Selatan yang telah membantu dan meminjamkan alat-alat penelitiannya.

\section{DAFTAR PUSTAKA}

1. BUNAWAS, Pemantauan Radioaktivitas Udara di Pabrik Kaos Lampu, Prosiding, 18-19 Agustus, Jakarta: BATAN, (1993) 190-194.

2. BUNAWAS DAN OTTO, Penentuan Diameter Aerosol Dengan Metoda Impaktor Bertingkat, Prosiding, 19-20 Nopember, Jakarta: PEBN BATAN, (1996) 314-318. 
3. EMLINARTI, BUCHARI DAN TURAHYATI, Konsentrasi Radionuklida Alam (Ra-226, Th-228 dan K40) Dalam Bahan Bangunan di Daerah Pekan Baru dan Sekitarnya, Prosiding, 26-27 Agustus, Jakarta: P3KRBiN BATAN, (1997) 149-157.
4. WU-LIEH HO, K.H. PHILIP, JJ. STUKEL, "The Attachment of RaA $\left({ }^{218} \mathrm{Po}\right)$ to monodispere Aerosol", Atmosphere Environment Vol.16 No.1 Great Britain (1982) 825-836. 